\title{
FAZENDO ANA PAZ: A METAFICÇÃO NO FAZER LITERÁRIO DE LYGIA BOJUNGA
}

Resumo: Esse artigo tem por objetivo estudar a metaficção na obra Fazendo Ana Paz (1991), de Lygia Bojunga, além de estabelecer suas correlações no tocante ao emprego das estratégias autorreferenciais. Almejamos refletir acerca desse recurso como motivador e instigador de um leitor mais reflexivo e crítico, haja vista que, ao se deparar com narrativas metaficcionais, ele não será um mero consumidor, mas, sim, um colaborador na construção dessas narrativas. A participação do leitor nessa (re)construção do texto literário acaba por ser um convite a experimentar os bastidores da produção artística, incitando-o a tornar-se mais reflexivo e a realizar uma leitura menos ingênua. $A$ metaficção gera certa instabilidade, pelo deslocamento do foco de atenção para o processo de criação da narrativa, muda-se o foco da história contada para o como essa história é contada. Além disso, o papel do leitor também é alterado, pois aqui ele passa a ser coautor, um colaborador do processo. Pensando em tais implicações, trazemos Fazendo Ana Paz (1991), uma vez que nos adentramos na ficção a partir de uma autora que, com um tom informal, conta ao seu leitor como surgiu a necessidade de escrever, expondo seu fazer literário, situando o leitor pelos caminhos da construção de suas narrativas, e também a confecção de seus personagens, deixando "à mostra" todo o processo.

Palavras-chave: Metaficção; Lygia Bojunga; Criador; Criatura.

Summary: The aim of this article is to analyze Metafiction in the work Fazendo Ana Paz (1991) from Lygia Bojunga; and to establish its correlations with the usage of self-reference strategies. We aim to examine this tool as a motivator and instigator for more critical and analytic readers, considering that, in this work, they would not be merely consumers, but contributors of its narrative production as well. Readers' participation in the (re)construction of the mentioned literary work evolves into an invitation to the backstage of its artistic production, encouraging them to be more concious about it; thus making them less gullible readers. Metafiction creates a certain instability due to shifting in focus. Narrative focus switches on to how the story is told 
instead. In addition, the reader's role also changes into co-authors and contributors of the entire process. In Fazendo Ana Paz (1991), Lygia Bojunga exposes her literary process and leads the readers through her narrative production as well as the creative process of her characters creation.

Keywords: Metafiction; Lygia Bojunga; Creator; Creature.

O conceito de literatura infantojuvenil, embora necessite de alteração, é assim compreendido talvez pelo fato de ocupar um "entre espaço", ou seja, é identificado entre a "literatura infantil" e a "literatura adulta". A ausência de uma definição rígida se instaura pelo fato do jovem ser concebido como aquele que não pode ser tratado como uma criança e também não pode ser levado muito a sério como um adulto, permeando o limiar de uma estratificação social. No decorrer dos anos, alguns fenômenos sociais e econômicos foram determinantes para que esse jovem passasse a ser concebido de forma diferente pela sociedade - com o desenvolvimento industrial e urbano as pessoas deixam o campo, surgem mais oportunidades de empregos, modificando assim, dentro das famílias a figura do jovem: percebe-se que investir na educação e na formação leitora desses jovens se faz necessário.

Porém, antes de nos aprofundarmos na questão da literatura juvenil, é necessário relativizar definições que tratam a juventude como sendo uma experiência vivida 
por todos: por um lado, temos um fenômeno a partir do determinante biológico, que seria a definição de um período cronológico da vida do indivíduo; por outro, temos o questionamento da unicidade do conceito de juventude, que propõe um tratamento diferenciado deste fenômeno de acordo com a heterogeneidade das trajetórias individuais pela estratificação social. Pierre Bourdieu (1983) afirma que assumir a juventude como um fenômeno unívoco, independente de uma divisão social, é uma tentativa de manipulação da realidade, pois não considerar as diferentes oportunidades vivenciadas por jovens de distintas classes sociais resultaria em análises caricaturais do fenômeno. Para ele, teríamos duas juventudes: a experimentada pelos filhos da burguesia e outra, bastante restrita e quase ausente, vivenciada pelos filhos dos operários.

José Machado Pais (1990) argumenta que a juventude deveria ser considerada "como aparente unidade", quando referida a uma fase da vida e como "diversidade", quando estão em jogo diferentes atributos sociais que fazem distinguir uns dos outros. Ele propõe a modificação da noção de cultura juvenil, reivindicando o conceito com o intuito de explorar questões específicas dos modos de vida dos jovens em seu dia a dia, defendendo a ideia da experiência, seja 
ela individual ou em formação de grupos, dessa juventude. Com isso, a identidade individual de cada jovem ganha importância, visando o desejo do reconhecimento. Isso direciona uma visão contemporânea da juventude para além daquele paradigma que se vincula apenas a ideia de como os jovens eram representados na sociedade, ou seja, considerando-os mais como sujeitos que precisavam ser amparados e cuidados para chegar à idade adulta sem transtornos.

Para Luis Antonio Groppo (2004), a juventude é uma realidade social e não uma "mistificação ideológica". Dessa forma, é preciso relacionar a juventude com outras categorias sociais como: a classe social, etnia, raça, religião e condição urbana. Ele defende que é preciso criar um norte, uma estrutura comum que compreenda quais são os valores estabelecidos para a atual juventude, visto que o período moderno buscou a "institucionalização" do curso da vida, na tentativa de homogeneizar os grupos etários, principalmente através do Estado e da escolarização. $\mathrm{Na}$ atualidade, essa "institucionalização" perde fôlego, o autor afirma ainda que, a sociedade contemporânea relativiza o conceito de juventude, fazendo com que o indivíduo tenha certa autonomia para compor sua identidade, seus 
comportamentos, seus valores e, sobretudo, que tenha a capacidade de transformá-los.

Diante de tais informações e ressaltando o fato do jovem ser visto pelo mercado como um consumidor em potencial (prova disso são os inúmeros objetos de consumo específicos como roupas, músicas, filmes, revistas e livros), se fez necessário criar uma literatura voltada para esse tipo de público, que não mais se interessa pelas histórias infantis, mas também não se sente preparado para as leituras adultas. No entanto, delimitar a faixa etária com exatidão parecenos inviável, justamente pelo fato da adolescência ser categorizada histórica e socialmente como uma "literatura de fronteira ou de intervalo", como definem José António Gomes (2007) e Maria Madalena Teixeira da Silva (2010; 2012).

A literatura juvenil é de extrema importância na formação do jovem leitor, além disso, encontra-se em pleno processo de consolidação, que em termos de qualidade estética nada deixa a desejar à "literatura adulta". Demarcada por um público que já passou pelo processo de alfabetização, mas que ainda tende a desenvolver suas competências no que tange os termos do uso da língua e da capacidade interpretativa a partir de uma linguagem rica e simbólica, 
que deve ser despertada por obras de qualidade, destinadas a esse público. Esse tipo de literatura revela peculiaridades marcadas por variedade e riqueza, além de inovadora em seu aspecto temático. Pode ser classificada em fantástica e realista.

A narrativa fantástica tende a se construir a partir dos contos de fadas, histórias populares e universos maravilhosos, no que tange contextos atemporais. Trata-se de recriações que se constituem por transformações no conteúdo moral, além das inversões de papéis: é muito comum encontrar princesas que não mais se submetem ao jugo da família ou marido, abandonando sua condição de fragilidade e dependência; reis tomados pela alienação e sem nenhum preparo, nem conhecimento para governarem; príncipes covardes e medrosos; além de bruxas de bom coração e fadas horrendas e de caráter duvidoso.

Já a narrativa realista, definida a partir de algo possível, pautada na verossimilhança, é classificada em duas correntes: idealista e realismo crítico. A primeira pode ser definida a partir de situações do dia a dia, omitindo o mundo de forma exageradamente conflitiva, resultando em um desfecho pautado no diálogo e cooperação. Enquanto o realismo crítico apresenta ao jovem leitor a realidade social e humana, 
onde os temas tangem o universo político, sexual, racial, ecológico, psicológico, familiar, além de vícios, depressão, violência doméstica, dentre outros, abordando questões que por muito tempo foram poupados. Essa tendência parece ser a mais recorrente na contemporaneidade, embora não tenha o objetivo de influenciar negativamente, mas sim, incitar a pensar e agir, visto que elas refletem os problemas sociais vivenciados por esses jovens, em especial, a violência e as questões econômico-culturais. Ao se deparar com tais narrativas, o jovem leitor, se identificará e assim, irá interessar-se por novos conhecimentos, compreendendo o funcionamento do mundo, neutralizando a alienação e estimulando a cidadania ativa e participativa.

Essas narrativas contemporâneas rompem com a literatura marcada pelo viés pedagógico e moralizante, que por muito tempo perdurou e assumem sua condição de arte capturando o seu próprio interesse, sem negligenciar as peculiaridades da obra literária, com isso, não se submete às exigências do mercado, mas valoriza sua condição de arte.

A qualidade estética que essas narrativas imprimem desde temas fraturantes à própria construção da linguagem, marcadas por experimentalismos e inovações, que envolvem o jovem leitor à reflexão da sua própria condição e do próprio 
ato da escrita. Dentre essas estratégias podemos ressaltar a metaficção, na qual Miguel de Cervantes já anunciava em sua obra Dom Quixote de La Mancha (1605), ao parodiar um romance de cavalaria, desmascarando certas convenções literárias. Pensando nisso, podemos afirmar que esse recurso não se trata de um fenômeno novo. No entanto, o que há de diferente é que após o século XIX, a metaficção aparece com mais frequência, de modo mais explícito e de diferentes formas: enquanto a poética do Romantismo se concentrava no autor e sua biografia, os realistas davam maior importância aos aspectos sociais e históricos do texto, levantando questões acerca da participação do leitor na composição da ficção.

Segundo Linda Hutcheon (1984), os textos modernos passaram a combater a imposição de um absoluto e autoritário significado do texto, afirmando que a metaficção textualmente autoconsciente nos leva ao conhecimento da complexa natureza da escrita, e acrescenta que a atual autoconsciência formal e temática da metaficção é paradigma da maioria das formas culturais do mundo pós-moderno, onde autorreferência e o processo de espelhamento infinito são frequentes.

A metaficção "brinca" com as possibilidades de significado e forma, visto que a autoconsciência que a permeia, inclui a 
importância do leitor ao adentrar no espaço literário, e sua participação parece estar tecida no interior da linguagem e da ficcionalidade do produto textual. A narrativa aconselha aquele que lê dentro de uma participação ativa no processo de produção de sentido, trabalhando para fazer com que seus leitores fiquem conscientes da produção e recepção do texto como produto cultural.

Enquanto alguns escritores e críticos compreendem a metaficção como uma ameaça ao gênero do romance, Hutcheon e Patricia Waugh (1984) acreditam que ela represente uma transformação do gênero, atribuindo ao romance a sua verdadeira identidade enquanto ficção. A metaficção, ao contrário do romance realista, mostra que não há um mundo de verdades absolutas e eternas, mas sim, construções provisórias, pautadas na instabilidade e flexibilidade, garantindo assim a sobrevivência do gênero. A ficção pode até estabelecer um elo com a vida, no entanto, não há intenção de espelhar o real, uma vez que a realidade é multifacetada. Os textos ficcionais se valem da linguagem, mas não imitam a natureza e a realidade como são, eles procuram estabelecer com essa realidade certa verossimilhança, que se materializa no mundo ficcional. Conforme afirma Hutcheon: 
O clássico romance realista de trama bem feita dá ao leitor a sensação de completude que sugere, por analogia, que a ação humana é de alguma forma inteira e significativa, ou o oposto, no caso da arte por si só que pode dar qualquer ordem ou sentido para a vida. O moderno, ambíguo romance pode sugerir, por outro lado, menos insegurança óbvia ao novo ou a falta de coincidência entre a necessidade do homem de ordem e de sua experiência real do caos do mundo contingente, de certa curiosidade sobre a capacidade da arte para produzir ordem "real", mesmo por analogia, através do processo de construção ficcional. (1984, p.19)

A metaficção gera essa instabilidade, pelo deslocamento do foco de atenção para o processo de criação da narrativa, muda-se o foco da história contada para o como essa história é contada. Além disso, o papel do leitor também é alterado, pois aqui ele passa a ser coautor, um colaborador do processo. Pensando em tais implicações, trazemos Fazendo Ana Paz (1991), de Lygia Bojunga, uma vez que nos adentramos na obra a partir de uma autora que, com um tom informal, conta ao seu leitor como surgiu a necessidade de escrever, expondo como surgiram mais dois livros: Livro - um encontro com Lygia Bojunga (1988) e Paisagem (1992). Dessa forma, Fazendo Ana Paz se localiza entre ambos, caracterizando uma "trilogia do livro", pois trata-se do fazer literário da autora, 
situando o leitor pelos caminhos da construção de suas narrativas e na confecção de seus personagens, deixando "à mostra" todo o processo. Somos introduzidos na narrativa a partir da fala: "Eu sempre gostei de ler livros de viagens; um dia me deu vontade de escrever um" (BOJUNGA, 1991, p.12). A partir daí, a narradora conta que ao se dispor a escrever tal livro, acaba saindo um bilhete escrito por uma menina chamada Raquel, personagem principal de $A$ bolsa amarela (1976), cheia de vontades e caprichos, essa personagem convence a sua "criadora" a se curvar aos seus desejos, tanto que a faz mudar de percurso. O leitor fica com a sensação de que a autora, por motivos maiores, é levada a abandonar sua ideia de origem, um livro de viagens, movido por uma personagem que insistia em ser criada. E essa experiência se repete, pela segunda vez, com Ana Paz:

Eu estava habituada a ver cada um dos meus personagens hesitar pra vir à tona: quase sempre ele era isso, e depois isso, e depois isso, antes de virar aquilo; passava de gente pra bicho, de mulher pra homem, de criança pra velho, até ser o que ele ia ficar; que devagarinho que ele abria a porta dentro de mim! Daí o meu susto com a Raquel: ela nem tocou a campainha: escancarou a porta, se aboletou no meu caderno, e só foi embora quando botei o ponto final no livro. Depois dela, tudo que é personagem que eu fiz voltou a aparecer devagar: abria uma fresta 
da porta, dava uma espiada, sumia, voltava, a fresta ia aumentando... E tinha dias que eu pensava: será que filho meu mais nenhum vai chegar feito a Raquel chegou? E um dia, aconteceu de novo: ela chegou e sem a mais leve hesitação foi me dizendo:

- Eu me chamo Ana Paz; eu tenho oito anos; eu acho o meu nome bonito.

(BOJUNGA, 1991, p.15-16)

Essa personagem surge em primeira pessoa, como se estivesse estabelecendo com sua própria "criadora" e leitor, certa proximidade, intimidade ao contar fatos de sua vida, como seu nascimento e sobre a carranca que implica no episódio da morte do pai.

Após esse episódio rememorativo da infância de Ana Paz, a narradora expõe que não consegue seguir adiante, e por mais que ela tente dar prosseguimento à narrativa, ela percebe que "o meu lápis foi esbarrando numa pergunta atrás da outra" (1991, p.19), bloqueando seu processo criativo:

Nossa! Empacar todo escritor empaca. Mas assim? tão depressa? Mal o livro começa? Fui ficando meio deprimida. Puxa, mas também que ingenuidade achar que a Ana Paz não ia mais me largar, por que que eu tinha achado? E que falta de maturidade também! Então eu ainda não tinha aprendido? (1991, p.20)

Conforme já mencionado, no início do texto, essa exposição por parte da autora no compor de suas personagens, 
dialoga com o que Linda Hutcheon (1984) afirma acerca da participação do leitor, ou de "coautor", focando assim no processo de produção da narrativa e "deixando à mostra" para que seu leitor perceba todas suas dificuldades no que tange o fazer literário:

Existe um conjunto de relações sociais entre produtor e público que talvez pudesse ser revolucionado por uma mudança nas forças de produção que iria transformar o leitor em um colaborador, em vez de um consumidor. Hoje, na metaficção, o artista reaparece não como um Deus, como criador romântico, mas como o fabricante de inscrição de um produto social que tem o potencial para participar na mudança social por meio de seu leitor. (1984, p.15)

Ao retomarmos a narrativa de Bojunga, nos deparamos com uma autora angustiada por se encontrar em um processo de "empacamento". Depois de algum tempo, surge outra personagem, a priori sem uma relação aparente com Ana Paz, na qual a narradora denomina "Moça-quese-apaixonou-pelo-Antônio", em um banco de uma praça no Rio de Janeiro. Além dessa moça, que nada ajudou a desembaraçar o "sumiço" de Ana Paz, surge uma terceira personagem denominada pela autora como "Velha". Essa personagem, já com seus oitenta anos, surge na narrativa com a vontade de viajar para o Rio Grande do Sul, à contra 
gosto de seu filho, com o objetivo de reviver e rememorar algo do seu passado, sua suposta infância, e "encontrar com duas personagens que andam desgarradas por aí [...]. Então eu virei a Ana Paz e a Moça-que-se-apaixonou-peloAntônio em duas amigas da Velha" (1991, p.36), organizando um encontro entre as três. Diante disso, podemos identificar a Velha como aquela personagem que produz todo o movimento de rememoração do seu próprio passado, entre eles, o da sua família e o de sua cidade natal, sugerindo assim, que é dela que surge a demanda da viagem interior, temporal e histórico-cultural, fato este que a aproxima da autora numa espécie de espelhamento: a personagem ficcional viaja para completar um trabalho de rememoração, enquanto "Lygia Bojunga" retorna ao Rio de Janeiro, levando consigo a sensação de dever cumprido.

Ao promover esse encontro das três, a Velha decide fazê-lo na casa de sua infância, onde a autora, sem muita dificuldade, resolve "levantar a casa":

Eu fiz ela toda de sobras. Uma sobra da casa do meu avô, outra da casa da minha tia, outra do apartamento da minha professora de inglês [...]. De cada morada eu tirava um pedaço, pra ir levantando a casa onde as minhas três mulheres iam se encontrar. (1991, p.37) 
Todas essas partes, ditas como "sobras", parecem ser fragmentos de memória selecionados pela autora, formando assim momentos da vida da Velha. Essa fragmentação pode ser identificada na própria narrativa, na construção dos personagens, no foco narrativo, além de traços autorreferenciais.

Temos também a passagem em que a Velha se depara com o "ela-mesma-ali-criança" configurado em um jogo temporal, visto que ocorre a simultaneidade do passado, representado por Ana Paz-criança e a Moça-que-se-apaixonou-peloAntônio, e a do presente através da Ana Paz-velha. Trata-se de duas personagens diferenciadas que se desprenderam, com a diferença apenas de que não vemos o processo de desdobramento, mas sim o produto, já que ambas são construídas de modo independente na narrativa. É como se se tratasse não de desdobramentos da mesma personagem, mas de três personagens distintas cujos percursos se cruzam no passado com o presente.

É isso! As três são a mesma! Não foi à toa que, quando fiz a moça e a velha, eu não dei nome nem pra uma nem pra outra: lá num fundão escuro da minha cuca eu já devia ter sacado o que eu só agora estou me dando conta. A Ana Paz vai crescer e se apaixonar pelo Antônio. E quando ela chega no inverno da vida ela vai sentir a urgência de voltar pra casa onde ela nasceu, onde ela viu acontecer 
a tragédia com o pai; ela vai querer juntar os pedaços dela, vai querer se encontrar com a menina e a moça que ela foi. $(1991$, p.42)

Concomitantemente, nos deparamos com uma autora que se mostra angustiada, por não conseguir construir o pai de Ana Paz, e com isso, o inacabamento da própria personagem, em virtude dessa não completude das partes adultas da menina. Esse ponto parece não estar resolvido na narrativa, embora não seja um aspecto frágil, pois ao abrir a cena da criação literária e deixar claro desde o princípio que é uma autora em dúvida, faz com que tais pontos obscuros se tornem verossímeis dentro da obra. A autora não consegue de maneira alguma levantar esse pai e mantê-lo em pé. Ele surge junto ao primeiro momento de Ana Paz, durante sua infância, e retorna em algumas memórias da Ana Paz-velha, o que gera uma crise nessa autora:

Tinha acontecido outra vez. A cena que eu estava fazendo se partia, o Pai me escapava, voltava pra morte dele; e não adiantava eu querer trazer ele pra página em branco: cada vez que eu começava a escrever o Pai ele voltava pra primeira cena do livro.

Empaquei.

Sentava de manhã pra escrever. Começava a brigar com as palavras. (1991, p.58)

A autora expõe sua vontade em criar uma personagem consistente, o tal pai que estava sendo criado não possuía 
essa aura de verossimilhança. Dentre tantas tentativas fracassadas que perpassam desde um pai "chato de galochas", "um pai superfechado", "boa praça", "um pai sonhador, romântico" (BOJUNGA, 1991, p.58-59 - grifo nosso), não deixaram a autora satisfeita, visto que não encontrava o tom correto desse personagem tão importante. E é justamente esse o ponto crucial da narrativa: se deparar com tantos questionamentos e dúvidas, olhar para todos eles e seguir adiante, envolvendo o leitor em seu "jogo criativo".

Com isso, é relevante perceber que, através do processo de dúvida, tentativa e erro, é que o Pai se constitui como personagem multifacetada e complexa, que valem como uma demonstração de algo maior que o produto final, ao passo que a solução parece estar em defini-lo como alguém cheio de contradições defeitos e qualidade: humano como todos nós, envolvido em processo de empatia.

Em muitos momentos, percebemos também, que a autora expõe antecipadamente fatos da narrativa:

Essa marca só vai começar a se apagar no dia que a Ana Paz se apaixona por um homem bem azeitado (e ajeitado) no sistema. Mas marca tão forte assim um dia tem que aparecer de novo. E aparece. Só que tarde. Mas não tarde demais: a Ana Paz-velha volta pra casa da infância, vai ser mediadora no conflito entre Menina e Moça, e durante 
esse processo ela se reaproxima da Casa e da Carranca: retoma o cumprimento da promessa que fez pro Pai... (1991)

Nota-se então que o que importa é o trabalho que se vai fazendo, como o próprio verbo no gerúndio do título do livro já diz: um contínuo fazer. Portanto, trata-se de uma obra infindável, onde o leitor pode trilhar vários caminhos de leitura, onde as três Anas podem ser lidas como emergências de energias afetivas que pareciam estar ocultas, provocando ou se deixando provocar, por uma autora que deixa "à mostra" o caminho trilhado. A atenção está focada no processo de criação de Lygia, pois deseja-se saber como a autora desmanchará os nós apresentados no processo de criação literária em uma obra concisa e coerente.

A contradição se estabelece desde o início da discussão metalinguística que: por um lado, temos em mãos a trama, concreta, editada e assinada por Lygia. Por outro, temos uma narrativa aberta, em discussão com todos seus percalços e dúvidas, e que se encontra em processo. Assistimos a uma narrativa onde a autora abre as possibilidades de enredo ao leitor, e apresenta mais dúvidas do que certezas em relação aos rumos dela, gerando muita angústia.

Os depoimentos da autora, cheia de dúvidas frente aos rumos das personagens, mesclam-se entre autora- 
personagem e sua criação, ao ponto de Ana Paz negociar com a autora seu destino dentro da trama:

- Ana Paz?... Por que você apagou a luz?... Eu sei que você taí, Ana Paz.

Acende a luz, sim? Ô, Ana Paz, quer acender essa luz?

- Só se você faz o meu pai.

- Eu não posso fazer o teu pai no escuro.

- Pode sim: eu já vi você escrever no escuro...

- Uma anotação, uns rabiscos. Mas não um Pai: acende essa luz

- Primeiro eu quero o meu pai. (1991, p.62)

Estamos diante de uma criatura que observa sua criadora em momentos de criação, é como se estivesse acompanhando a autora, mesmo que sorrateiramente. Trata-se de uma personagem que parece adquirir vida fora da trama, pois elas compartilham memórias: esse fato confirma a presença constante das personagens no mundo interno da autora, de onde são levantadas conforme a necessidade de criação. Tudo isso, nos remete que, para Lygia Bojunga, construir uma personagem de ficção assemelha-se ao ato de dar à luz e conduzir o ser criado até a autonomia completa, é o que acontece com Ana Paz, pois ela consegue negociar os rumos de sua vida, embora não consiga convencer a autora criar o 
Pai, que, segundo ela, esse pai "nem sabe ficar em pé". As discussões entre ambas chegam ao ponto de Ana Paz acusar a autora de "não conseguir fazer mais ninguém", levando-a desistir momentaneamente de desenrolar os problemas encontrados no processo criativo.

A narrativa segue expondo seus tropeços, pausas, engasgos assim como o próprio fazer do escritor de ficção, com isso, já ao final da obra, a autora encontra uma solução para toda angústia acerca do inacabamento de seus personagens, no "rasgar" de sua ficção, gerando uma revolta em Ana Paz, que ressalta aquilo que considera os pontos altos da história, reivindicando seu direito de existir como personagem ficcional, apesar das lacunas apresentadas:

- Você não tá resolvida, vê se entende!

- Mas por que que eu não posso ser assim mesmo?

- Assim mesmo o quê?

- Assim: não resolvida, feito você diz, descosturada, mal acabada, tanto pedaço de mim rasgado (sabia que você me rasgou demais?). Você sonhou pra mim uma vida toda bem feita, só que a tua ideia não deu certo e eu fiquei desse jeito. Mas por que que você precisa rasgar o que eu fiquei? Por que que você não pode me contar pros outros assim? Desacertada, inacabada, esperando a luz que, um dia, vai se acender (ou não) em tudo que é pedaço que eu tenho de 
escuridão? Puxa vida! Eu nasci pra viver num livro! Livre! (você sabe tão bem que não tem nada mais livre que um livro). (1991, p.88-89)

É através do diálogo entre criador e criatura, e a tentativa de negociar a trajetória da protagonista, a fixação do olhar justamente nos tropeços do processo criativo que permeiam as principais características dessa obra. Neles, o leitor acompanha o descortinar do processo de criação literária, desmistificando o autor, ao passo que é conhecido como o detentor de todo o destino da ficção.

Com isso, estamos diante de uma escritora que se reafirma como escritora consciente elevando seu leitor, ao convidá-lo à reflexão, conforme Patrícia Waugh (1984) reflete acerca do papel do leitor diante de um romance metaficcional, enquanto elemento que atualiza o texto, preenchendo os espaços que há entre o mundo empírico e o mundo ficcional. Para tanto, afirma que entram em jogo conhecimentos linguísticos, os elementos objetivos e os subjetivos que fazem o leitor reavaliar sua relação com ambos os mundos. A narrativa metaficcional traz, ao mesmo tempo, liberdade e responsabilidade para o leitor, pois ele tem a liberdade de participar ativamente do processo de interpretação da obra, mas é sua responsabilidade colaborar com a produção desses textos, ao invés de consumi-los passivamente: 
Metaficção, então, não abandona "o mundo real" para os prazeres narcisistas da imaginação. O que ela faz é reexaminar as convenções do realismo, a fim de descobrir - através da sua própria auto-reflexão uma forma de ficção que é culturalmente relevante e compreensível para os leitores contemporâneos. Em nos mostrar como a ficção literária cria seus mundos imaginários, a metaficção nos ajuda a compreender como a realidade que vivemos no dia a dia é igualmente construída, de forma semelhante na "escrita". (WAUGH,1984, p.18)

Dessa forma, podemos entender que Patricia Waugh reitera a literatura como um caminho privilegiado para se pensar o mundo, haja vista que o assentamento desse mundo criado como se fosse real ocorre unicamente via linguagem. Assim sendo, a metaficção revela-se como estratégia pela qual se explora a relação entre realidade e ficção, criador e criatura, o que dialoga com o procedimento que Lygia Bojunga desenvolve em Fazendo Ana Paz.

\section{REFERÊNCIAS}

BOJUNGA, Lygia (1991). Fazendo Ana Paz. Rio de Janeiro: Agir. (1992). Paisagem. Rio de Janeiro: Agir. (2009). Livro - um encontro. 34.ed. Rio de Janeiro: Casa Lygia Bojunga.

BOURDIEU, Pierre (1983). A juventude é apenas uma palavra. Questões de sociologia.

CERVANTES, Miguel de (1983). O Engenhoso fidalgo D. Quixote de la Mancha. Rio de Janeiro: Editora Nova Aguilar. 
GROPPO, Luís Antonio (2004). "Dialética das juventudes modernas e contemporâneas". Revista de Educação do Cogeime, 13(25), Dez. 9-22. In https://www.metodista.br/revistas/revistas-cogeime/index.php/ COGEIME/article/view/629 Acesso em 17.Set.2019.

HUTCHEON, Linda (1984). Narcissistic narrative: the metaficcional paradox. 2.ed. New York: Methuen.

PAIS, José Machado (1990). "A construção sociológica da juventude: alguns contributos". Análise social, 25(105-106), 139-165.

WAUGH, Patricia (1984). Metafiction: the Theory and Practice of SelfConscious Fiction. London; New York: Methuen.

Gabriela Trevizo Gamboni é Doutoranda, Mestre e Especialista em Literatura e Crítica literária pela PUC-SP.

ORCID iD: https://orcid.org/0000-0001-5720-0829 